\title{
METÓdOS NÃO FARMACOLÓGICOS NO MANEJO DA DOR EM RECÉM NASCIDOS
}

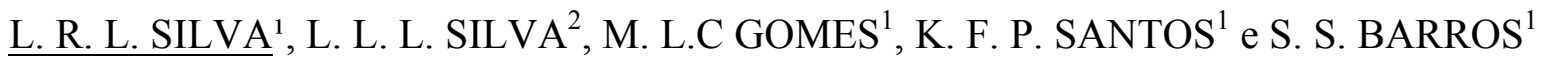 \\ ${ }^{1}$ Universidade Federal de Pernambuco, Centro de ciências da Saúde, Departamento de \\ Ciências Farmacêuticas \\ ${ }^{2}$ Universidade Estadual de Pernambuco, Residência de Enfermagem Obstétrica \\ E-mail para contato: laylarafaeellaa@gmail.com
}

\begin{abstract}
RESUMO - O trabalho objetivou-se em expor conhecimentos de cunho observacional em uma Unidade de Terapia Neonatal em um hospital escola de Recife-PE. Tratando-se de um estudo observacional realizado no primeiro semestre de 2017, com os descritores: "dor", "recém-nascido", "métodos não farmacológicos". Desta forma foram utilizados métodos não farmacológicos para o tratamento e alívio da dor de RNs através da Sucção não nutritiva, Método Canguru e Solução Glicosilada, não ocasionando riscos de cunho físico ou psicológico. No entanto em se tratando dos beneficios trazidos, mostrou ter um potencial inovador para as ciências da saúde abrangendo principalmente à segurança ao paciente.
\end{abstract}

Palavras chaves: Dor; Recém-Nascidos; Métodos não Farmacológicos.

ABSTRACT: The objective of this study was to present observational knowledge in a Neonatal Therapy Unit at a school hospital in Recife-PE. This is an observational study conducted in the first half of 2017, with the descriptors: "pain", "newborn", "non-pharmacological methods". In this way non-pharmacological methods for the treatment and relief of the pain of RNs through Non-nutritive Suction, Kangaroo Method and Glycosylated Solution were used, not causing physical or psychological risks. However, when dealing with the benefits brought, it has shown an innovative potential for the health sciences, mainly covering patient safety.

Keywords: Ache; Newborns; Non-Pharmacological Methods.

\section{INTRODUÇÃ̃O}

Os avanços tecnológicos relacionados ao processo intensivista neonatal contribuíram para aumentar a sobrevida de recém-nascidos criticamente doentes, entretanto, os estímulos dolorosos e desconfortos causados também se elevaram. Por anos, o processo de dor não teve a devida atenção por acreditar que o neonato dispunha de uma mielinização incompleta e sistema nervoso central imaturo, o que resultou numa inadequação em seu tratamento (ALVES et al., 2011). \{7\}

Atualmente é plenamente aceito que tanto o RN a termo como o pré-termo apresentam todos os componentes anatômicos, funcionais e neuroquímicos essenciais para a nocicepção, ou seja, para a recepção, transmissão e integração do estímulo doloroso (SCOCHI, CARLETTI e NUNES, 2006). 
Tomando como base estudos realizados e citados em algumas referências pesquisadas, recém-nascidos, principalmente os prematuros que necessitam de cuidados invasivos para sobreviver, precisam de maior atenção. Todavia, observam-se abordagens da dor baseadas muito mais na experiência cotidiana do que em definições literárias, as quais decorrem de acordo com as necessidades de cada paciente, tendo como exemplo: necessidade de sondagem orogástrica, aspiração de secreção e alimentação, administração medicamentosa intramuscular, punsão venosa, intubação oro traqueal entre tantos outros. Tendo em vista a quantidade de métodos invasivos para a estabilização do quadro clínico, manutenção da vida e profilaxia de patologias, os profissionais de saúde que lidam para com esses pacientes viram a necessidade de realizar manejo da dor iatrogênica de forma segura e não farmacológica, visto que há uma grande suscetibilidade a polifarmacia em pacientes de UTI.

\section{MATERIAIS E MÉTODOS}

Trata-se de um estudo observacional com abordagem descritiva, realizado no primeiro semestre de 2017 em uma Unidade de Terapia Intensiva neonatal de um Hospital Escola de Recife - PE. O presente estudo não ocasionou riscos de cunho mortal, físico e/ ou psicológico, pois se isentava de contato direto com pacientes e profissionais da instituição. No que tange aos benefícios trazidos pelo mesmo, o problema desenhado mostrou um potencial inovador para as ciências da saúde, abrangendo principalmente a segurança do paciente. Não houve necessidade de aprovação de um Comitê de Ética em pesquisa por se tratar de um estudo de cunho observacional sem ter sido aplicado questionários, entrevistas ou qualquer tipo de coleta de dados ligados diretamente à pessoa humana.

\section{RESULTADOS E DISCUSSÃO}

Durante o período de coleta de dados, os autores puderam observar a rotina do serviço em que estavam lotados e descrever quais procedimentos eram usados para chegar ao problema de pesquisa. Desse modo, foram descritos alguns métodos de alívio da dor no RN sem apoio de fármacos analgésicos e apresentam-se a seguir:

- O método Canguru;

- Sucação não nutritiva;

- Uso da sacarose;

Em duas pesquisas, uma nacional e outra internacional, autores registraram que a eficácia do método canguru ultrapassa o alívio da dor, uma vez que envolve a humanização da assistência ao RN. Ela consiste em uma tecnologia humana que visa ao cuidado de prematuros de baixo-peso, e tem como base a trilogia; calor, amor e leite materno. $\{4\}$

A Academia Americana de Pediatria e a Sociedade Pediátrica Canadense recomendam, desde 2000, uso da sacarose como método de alívio da dor durante procedimentos de rotina em Unidades de Terapia Intensiva, como a aspiração e punção. $\{5\}$ A ação analgésica corre devido a liberação de opióides endógenos e pode ser comprovada pela análise de parâmetros comportamentais e fisiológicos $\{1\}$. Desse modo, contatou-se na UTI em que o estudo foi realizado que os sinais vitais comparados em dois momentos, um sem uso sacarose, e no outro com uso da sacarose, mediante a utilização de métodos invasivos nos RNs, pôde-se observar 
uma normalização dos níveis de Pulso, Respiração, diminuição ou ausência do choro, e elevação da Saturação de Oxigênio.

Os estudos mostram que o uso da sacarose e da Sucção não nutritiva, quando utilizadas separadamente, tem efeito analgésico quando comparados com a água estéril, porém sua associação potencializa a analgesia. Os principais pontos observados para verificar se houve diminuição da dor foram o choro, a frequência cardíaca, a frequência respiratória, a saturação de oxigênio, a expressão facial e as escalas comportamentais.

A dor física ou psicológica decorre habitualmente de uma injúria aos diversos órgãos do sentido, ou seja, os procedimentos invasivos, como punção, sondagem e outros, necessários para salvar vidas, agridem a pele e mucosas (tato), com quebra de continuidade e dor. $\{6\}$ Assim como os ruídos, a luminosidade, os sabores e os odores desagradáveis do ambiente hospitalar provocam desconforto aos olhos, aos ouvidos, ao olfato e à gustação. Estes pacientes se sentem incomodados e desconsolados, o que pode modificar, inclusive, a sua homeostase. O corpo responde à dor não tratada por aumento da liberação de hormônios do estresse, que pode ser associada ao crescimento da morbidade e mortalidade em curto período.

\section{CONCLUSÃO}

Desta forma foi constatada a eficácia e importância do conhecimento e utilização das técnicas demonstradas para melhoria do tratamento dos profissionais de saúde para com os RNs, assim como para o esclarecimento da população, de modo inovador e que traz benefícios importantes e simples para a prática dos mesmos. E em se tratando dos benefícios trazidos é válido constatar que não houve riscos, para com os pacientes, de cunho mortal, físico ou psicológico.

\section{REFERÊNCIAS}

GASPARDO, Cláudia M.; LINHARES, Maria Beatriz M.; MARTINEZ, Francisco E. A eficácia da sacarose no alívio de dor em neonatos: revisão sistemática da literatura. Jornal de Pediatria. Rio de Janeiro, 2005; 81(6):435-42.

Hennig MAS, Gomes MASM, Gianini NOM. Conhecimentos e práticas dos profissionais de saúde sobre a "atenção humanizada ao recém-nascido de baixo peso — método canguru". Rev Bras Saúde Matern Infant. 2006;

GUINSBURG, Ruth. Avaliação e Tratamento da Dor no Recém-Nascido. Jornal de Pediatria. 1999, Vol. 75, N³

(4) Venancio SI, Almeida H. Método canguru: aplicação no Brasil, evidências científicas e impacto sobre o aleitamento materno. J Pediatr. 2004; 80(5):173-80.

(5) Eficácia analgésica da sacarose e sucção não-nutritiva em recém- nascidos hospitalizados: revisão de literatura- https://interfisio.com.br/eficacia-analgesicada-sacarose-e-succao-nao-nutritiva-em-recem-nascidos-hospitalizados-revisaode-literatura/ - acesso em: 09/12/2017 
(6) Farias LM, Rêgo RMV, et al. Cuidados de enfermagem no alívio da dor em recém-nascidos: Revisão integrativa-2011-

http://www.revistarene.ufc.br/vol12n4_html_site/a26v12n4.html- acesso em: 09/12/2017.

(7) Nogueira BE, et al. Dor e tratamento não farmacológico em recém-nascido: revisão narrativa- 2013-http://www.efdeportes.com/efd180/dor-emrecem-nascido.htm. acesso em: 09/12/2017.

\section{AGRADECIMENTOS}

Agradecemos em primeiro momento ao nosso Orientador, Lucas Leonardo de Lima Silva, pela oportunidade para com o estudo observacional realizado, assim como de aprofundarmos no quesito inovação em saúde. Objetivando propiciar aos pacientes, melhores condições de bem estar, assim como prevenção do que poderia ocorrer durante procedimentos corriqueiros, que acontecem nos hospitais em geral, e poucas vezes dão-se a importância e notoriedade para com projetos inovadores e construtivos para as ciências da saúde em geral.

Assim como ao $5^{\circ}$ EBIT por proporcionar-nos a oportunidade, de quem sabe, expor os conhecimentos adquiridos durante o primeiro semestre de 2017. 